\title{
Is the Content of Textbooks on the Evaluation of a Patient in Respiratory Distress Adequate?
}

\author{
Aiman Tulaimat MD, Aiyub Patel MD, Bhaven Shah MD, \\ and Stephen W Littleton MD
}

\begin{abstract}
BACKGROUND: The ability to rapidly and precisely evaluate patients in respiratory distress is essential. Due to limited opportunities for formal instruction during training, textbooks are the main educational source to teach junior physicians how to interpret the signs of respiratory distress. The quality of the textbook content relevant to respiratory distress is unknown. OBJECTIVE: To examine the content on the evaluation of a patient in respiratory distress in a representative sample of textbooks and Internet resources. METHODS: Two physicians individually reviewed the most recent edition of 21 standard textbooks from a variety of specialties. Smartphone applications, UptoDate, and MD Consult were examined. Each physician reviewed the source for 14 different signs. For each sign, the reviewers determined 3 parameters: a mention of the sign, its pathophysiology, and its detection. The reviews were compared for discrepancies, and a third reviewer resolved them. RESULTS: The normal respiratory rate was mentioned in $10(48 \%)$ of textbooks, and ranged between 10 and 22 breaths/min. Each sign was mentioned by a mean of $45 \pm 26 \%$ of the textbooks. The pathophysiology of the signs was described by a mean of $33 \pm 30 \%$ of the textbooks. The most and least commonly mentioned inspection signs were cyanosis and retraction of suprasternal notch, respectively. They were mentioned in $20(95 \%)$ and $4(19 \%)$ textbooks, respectively. The most and least commonly mentioned palpation signs were thoracoabdominal asynchrony or paradox and tracheal tug, respectively. They were mentioned in $17(81 \%)$ and 4 (19\%) textbooks, and their pathophysiology was described in $15(71 \%)$ and $4(19 \%)$ textbooks, respectively. The reviewers also found inconsistency in the descriptions of the meaning of scalene muscle contraction and thoracoabdominal asynchrony and paradox. CONCLUSIONS: The content of the reviewed textbooks on the evaluation of respiratory distress is inconsistent and deficient. Key words: patient evaluation; respiratory distress; medical education; textbooks. [Respir Care 2012;57(3): 404-412. () 2012 Daedalus Enterprises]
\end{abstract}

\section{Introduction}

Patients who are acutely unstable constitute a minority of the patients seen by physicians, but represent a majority

The authors are affiliated with the Pulmonary and Critical Care Division, Department of Medicine, Hospital of Cook County, Chicago, Illinois.

The authors have disclosed no conflicts of interest.

Correspondence: Stephen W Littleton MD, Pulmonary and Critical Care Division, Department of Medicine, Hospital of Cook County, 1900 W Polk Street, Room 1415, Chicago IL 60612. E-mail: slittleton@ cookcountyhhs. org.

DOI: $10.4187 /$ respcare. 01112 among those with substantial morbidity and mortality. ${ }^{1}$ Respiratory distress is one such manifestation of instability. Physicians either describe respiratory distress with vague, semi-quantitative, subjective terms such as "mild," "moderate," or "severe," or they objectively determine the respiratory rate, describe the patient's body posture, and detect respiratory muscle contraction. The evaluation of a patient in respiratory distress is a crucial skill for any physician, nurse, or respiratory therapist who practices inpatient or emergency medicine.

The skills necessary to correctly manage patients in respiratory distress can be divided into 3 categories: cognitive, psychomotor, and affective. ${ }^{2}$ The cognitive skills include understanding basic respiratory physiology and anatomy, and interpreting the signs of respiratory distress. 
The psychomotor skills include conducting a physical examination and executing any necessary procedures (eg, endotracheal intubation). The affective skills consist of leadership and management skills during a crisis situation. Similar to other areas in medicine, the cognitive and psychomotor skills particular to respiratory distress are acquired through both instruction at the bedside and by reading medical textbooks. ${ }^{3,4}$ Severe respiratory distress requires urgent attention that might not allow ample time for bedside training; therefore, the textbook serves as a cornerstone in providing the most comprehensive instruction. The quality and consistency of textbook content on the evaluation of respiratory distress is unknown.

Because of the important role textbooks play in this area, we reviewed a representative sample of medical textbooks and electronic resources to evaluate their content on the physical examination of a patient in respiratory distress.

\section{Methods}

To assess the content of textbooks on the examination of a patient with respiratory distress, 2 reviewers screened the most recent editions of a wide variety of general and specialty medical textbooks and selected 21 textbooks for review (Table 1). The textbooks were selected by informally asking colleagues in a variety of specialties which textbooks they would consult regarding respiratory distress or respiratory failure. The books were obtained from local libraries and not from the publisher. We also noted whether each textbook had a version available online. Each book was reviewed to determine if it included: a chapter or section on respiratory distress, respiratory failure, indications for mechanical ventilation, and indications for intubation; the normal range of respiratory rate and how to interpret its abnormalities; and a group of signs related to the dysfunction of the respiratory system (Table 2). For each sign, the reviewers determined 3 parameters: a mention of the sign, its pathophysiology, and its detection. The reviewers selected statements that were representative of textbook content about the signs. Chapters on respiratory distress, respiratory failure, physical examination, and mechanical ventilation (if present) were all examined for statements on each sign.

To achieve this task, each reviewer screened the table of contents of each book to identify the chapters specifically devoted to the care of a patient with respiratory distress (eg, respiratory system diseases, respiratory failure, physical examination of respiratory system, mechanical ventilation) and examined the index of each book for key words concerning respiratory distress evaluation (all signs mentioned in Table 2, as well as respiratory rate, tachypnea, respiratory failure, intubation, mechanical ventilation, respiratory distress, etc). Each reviewer completed a standardized form independently.

\section{QUICK LOOK}

\section{Current knowledge}

Respiratory distress is a common and potentially lifethreatening condition that must be readily recognized by clinicians. Since training bedside personnel in this skill at the bedside is difficult, textbooks and online resources are important.

\section{What this paper contributes to our knowledge}

Textbooks addressing respiratory distress are frequently contradictory and sometimes provide misinformation. A more uniform approach in education and training is required.

The forms of the 2 reviewers were compared for discrepancies, and a third reviewer resolved them.

For the Internet resource UptoDate in Pulmonary, Critical Care, and Sleep Medicine, we searched the term "acute respiratory failure." Table 3 lists the topic reviews that were analyzed, which topic reviews included some results, and which topic reviews contained no results.

We also performed an informal survey of house staff regarding which Internet resources they use. We also searched the "app stores" of both the Apple and Android platforms with the following terms: "pulmonary," "mechanical ventilation," "respiratory distress," and "critical care."

\section{Results}

\section{Chapters}

All of the reviewed textbooks contained a chapter on the respiratory system. Fourteen (67\%) textbooks had a chapter or section specifically on respiratory failure. Only 8 (38\%) textbooks had a section or chapter on respiratory distress. Seven (33\%) textbooks mentioned indications for mechanical ventilation. Seven (33\%) textbooks mentioned indications for endotracheal intubation.

\section{Overall Textbook Quality}

Table 4 lists the textbooks in order of quality. Egan's Fundamentals of Respiratory Care included the most signs and descriptions, earning $77 \%$ of all possible points. Runner-up was Tobin's Principles and Practice of Mechanical Ventilation. Overall, textbooks on respiratory care and physical examination fared better, and those focused on critical care and anesthesia fared worse.

\section{Signs}

Overall, each sign was mentioned by a mean of $45 \pm$ $26 \%$ of the textbooks. The pathophysiology of each sign 


\section{Textbooks on the Evaluation of a Patient in Respiratory Distress}

Table 1. Textbooks Reviewed

\begin{tabular}{|c|c|c|c|c|c|}
\hline Textbook & Author/Editor & Edition & Year & $\begin{array}{l}\text { International Serial } \\
\text { Book Number }\end{array}$ & $\begin{array}{l}\text { Online } \\
\text { Version }\end{array}$ \\
\hline \multicolumn{6}{|l|}{ Internal Medicine } \\
\hline Harrison's Principles of Internal Medicine ${ }^{5}$ & Fauci et al & 17 & 2008 & $978-0-07-146633-2$ & Yes \\
\hline Cecil Medicine $e^{6}$ & Goldman, Ausiello & 23 & 2008 & $978-1-4160-2805-5$ & Yes \\
\hline \multicolumn{6}{|l|}{ Physical Diagnosis } \\
\hline Bates' Guide to Physical Examination and History Taking ${ }^{7}$ & Bickley, Szilagyi & 9 & 2007 & $0-7817-6718-0$ & Yes \\
\hline Physical Examination \& Health Assessment ${ }^{8}$ & Jarvis & 5 & 2008 & $978-1-4160-3243-4$ & No \\
\hline Textbook of Physical Diagnosis: History and Examination ${ }^{9}$ & Swartz & 5 & 2006 & $141600307 X$ & No \\
\hline Sapira's Art \& Science of Bedside Diagnosis ${ }^{10}$ & Orient & 3 & 2005 & $0-7817-5731-2$ & No \\
\hline \multicolumn{6}{|l|}{ Mechanical Ventilation } \\
\hline Principles and Practice of Mechanical Ventilation $^{11}$ & Tobin & 2 & 2006 & $0-07-144767-9$ & Yes \\
\hline Essentials of Mechanical Ventilation ${ }^{12}$ & Hess, Kacmarek & 2 & 2002 & $0-07-135229-5$ & No \\
\hline Mechanical Ventilation: Physiological and Clinical Applications ${ }^{13}$ & Pilbeam, Cairo & 4 & 2006 & $0-323-03236-2$ & Yes \\
\hline \multicolumn{6}{|l|}{ Critical Care Medicine } \\
\hline Principles of Critical Care ${ }^{14}$ & Hall et al & 3 & 2005 & $0-07-141640-4$ & Yes \\
\hline Principles and Practice of Intensive Care Monitoring ${ }^{15}$ & Tobin & 1 & 1998 & $0-07-065094-2$ & No \\
\hline Irwin and Rippe's Intensive Care Medicine $e^{16}$ & Irwin, Rippe & 6 & 2008 & $978-0-7817-9153-3$ & Yes \\
\hline $\begin{array}{l}\text { Critical Care Medicine: Principles of Diagnosis and } \\
\text { Management in the Adult }{ }^{17}\end{array}$ & Parrillo, Dellinger & 3 & 2008 & $978-0-323-04841-5$ & No \\
\hline \multicolumn{6}{|l|}{ Respiratory Medicine } \\
\hline Clinical Respiratory Medicine ${ }^{1}$ & Spiro et al & 3 & 2008 & $978-0-323-04825-5$ & No \\
\hline Murray and Nadel's Textbook of Respiratory Medicine ${ }^{18}$ & Mason et al & 4 & 2005 & $0-7216-0327-0$ & Yes \\
\hline Fraser and Pare's Diagnosis of Diseases of the Chest ${ }^{19}$ & Fraser et al & 4 & 1999 & $0-7216-6194-7$ & No \\
\hline Comprehensive Respiratory Care C $^{20}$ & Dantzker et al & 1 & 1995 & $0-7216-2844-3$ & No \\
\hline Egan's Fundamentals of Respiratory Care ${ }^{21}$ & Wilkins et al & 8 & 2003 & $0-323-01813-0$ & No \\
\hline \multicolumn{6}{|l|}{ Anesthesia } \\
\hline Miller's Anesthesia ${ }^{22}$ & Miller & 6 & 2005 & $0-443-06618-3$ & Yes \\
\hline \multicolumn{6}{|l|}{ Emergency Medicine } \\
\hline Harwood-Nuss' Clinical Practice of Emergency Medicine ${ }^{23}$ & Wolfson & 4 & 2005 & $0-7817-5125-X$ & No \\
\hline Emergency Medicine: A Comprehensive Study Guide ${ }^{24}$ & Tintinalli et al & 6 & 2004 & $0-07-138875-3$ & Yes \\
\hline
\end{tabular}

was described by a mean of $33 \pm 30 \%$ of the textbooks. Only $27 \pm 22 \%$ of the textbooks explained the meaning of each sign.

\section{Inspection Signs}

Of the inspection signs, each sign was mentioned by a mean of $48 \pm 27 \%$ of the textbooks (Fig. 1). Their pathophysiologic meaning was described by a mean of $25 \pm 21 \%$ of the textbooks. Cyanosis was the most commonly mentioned sign. It was mentioned in $20(95 \%)$ textbooks, and its pathophysiology was discussed in 17 (81\%) textbooks. The least mentioned sign was retraction of the suprasternal notch. Three (14\%) textbooks mentioned it and described its pathophysiology. The normal range of respiratory rate was mentioned in only $10(48 \%)$ textbooks, and the interpretation of its abnormalities was discussed in 7 (33\%).

\section{Palpation Signs}

Of the palpation signs, each sign was mentioned by mean of $48 \pm 24 \%$ of textbooks (Fig. 2). The pathophysiology of each sign and the method of detection were in
$32 \pm 23 \%$ and $9 \pm 13 \%$ of the textbooks, respectively. The most commonly mentioned sign was thoracoabdomi-

Table 2. Signs of Respiratory Distress 


\section{Textbooks on the Evaluation of a Patient in Respiratory Distress}

Table 3. UptoDate Topic Reviews Analyzed

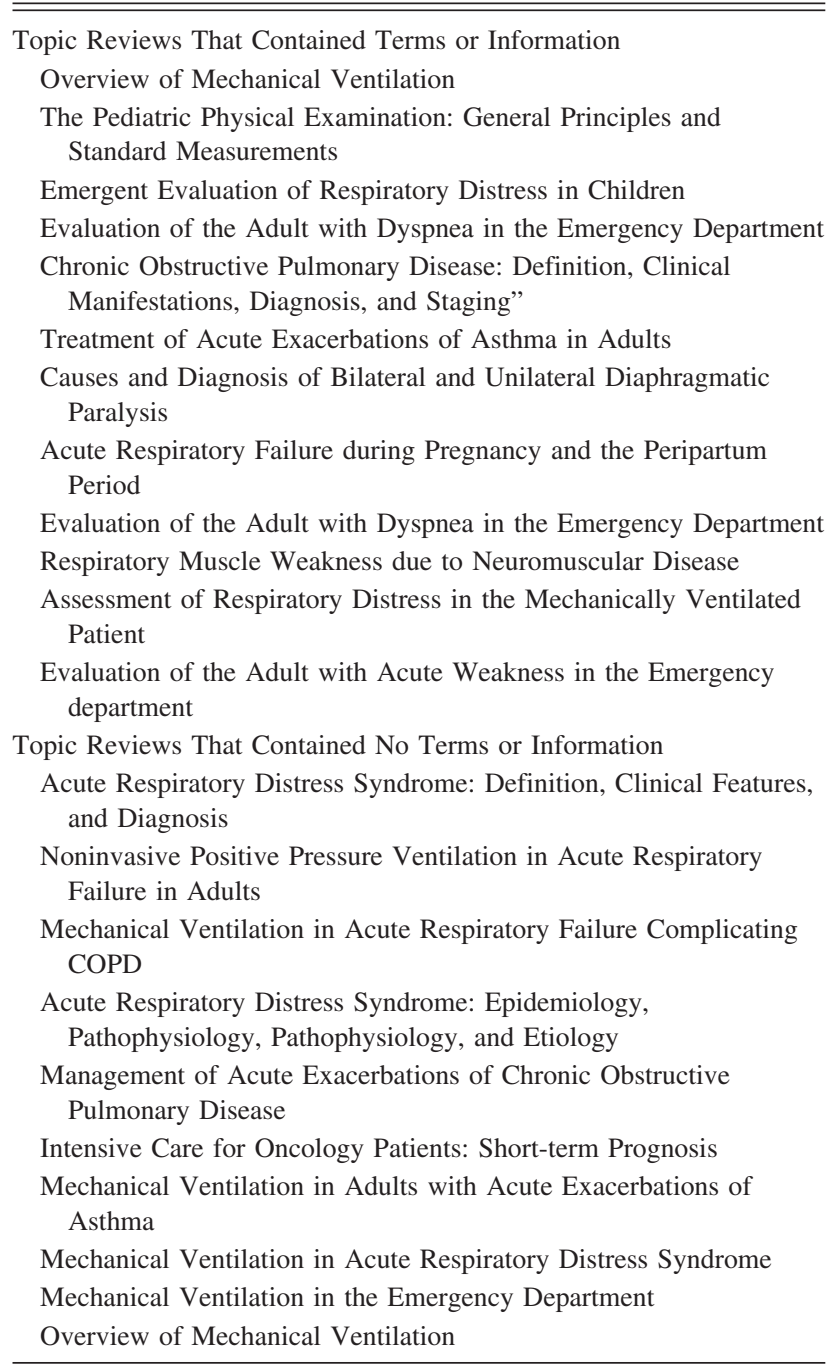

nal asynchrony or paradox. It was mentioned in $17(81 \%)$ books, but only 15 (71\%) discussed its pathophysiology. The least mentioned sign was tracheal tug. It was mentioned in $4(19 \%)$ books, $4(19 \%)$ discussed its pathophysiology, and only one (5\%) described how to detect it.

\section{Individual Signs}

Body Posture. Fourteen (67\%) textbooks mentioned sitting as a sign of respiratory distress, 7 (33\%) described sitting in the tripod position, and 6 (29\%) explained how the tripod position facilitates the action of the rib cage muscles. One (5\%) textbook mentioned that holding the head off the pillow enhances the action of the sternocleidomastoid.

Abnormal Breathing Sounds. Seventeen (81\%) books mentioned this sign. All 17 mentioned stridor. Two (10\%)
Table 4. Textbook Quality, Expressed as a Percentage of Possible Points*

\begin{tabular}{|c|c|}
\hline Textbook & $\begin{array}{c}\% \text { of } \\
\text { Possible Points }\end{array}$ \\
\hline Egan's Fundamentals of Respiratory Care ${ }^{21}$ & 77 \\
\hline $\begin{array}{l}\text { Principles and Practice of Mechanical } \\
\text { Ventilation }{ }^{11}\end{array}$ & 69 \\
\hline UptoDate $\dagger$ & 69 \\
\hline Comprehensive Respiratory Care ${ }^{20}$ & 63 \\
\hline Clinical Respiratory Medicine $^{1}$ & 58 \\
\hline Sapira's Art \& Science of Bedside Diagnosis ${ }^{10}$ & 42 \\
\hline $\begin{array}{l}\text { Murray and Nadel's Textbook of Respiratory } \\
\text { Medicine }{ }^{18}\end{array}$ & 42 \\
\hline $\begin{array}{l}\text { Bates' Guide to Physical Examination and } \\
\text { History Taking }{ }^{7}\end{array}$ & 40 \\
\hline $\begin{array}{l}\text { Textbook of Physical Diagnosis: History and } \\
\quad \text { Examination }{ }^{9}\end{array}$ & 40 \\
\hline $\begin{array}{l}\text { Mechanical Ventilation: Physiological and } \\
\text { Clinical Applications }{ }^{13}\end{array}$ & 37 \\
\hline Harrison's Principles of Internal Medicine ${ }^{5}$ & 35 \\
\hline $\begin{array}{l}\text { Fraser and Pare's Diagnosis of Diseases of } \\
\text { the Chest }{ }^{19}\end{array}$ & 33 \\
\hline $\begin{array}{l}\text { Principles and Practice of Intensive Care } \\
\text { Monitoring } 15\end{array}$ & 31 \\
\hline Irwin and Rippe's Intensive Care Medicine ${ }^{16}$ & 31 \\
\hline $\begin{array}{l}\text { Critical Care Medicine: Principles of } \\
\text { Diagnosis and Management in the Adult }{ }^{17}\end{array}$ & 31 \\
\hline $\begin{array}{l}\text { Harwood-Nuss' Clinical Practice of } \\
\text { Emergency Medicine }\end{array}$ & 31 \\
\hline $\begin{array}{l}\text { Emergency Medicine: A Comprehensive Study } \\
\quad \text { Guide }^{24}\end{array}$ & 31 \\
\hline Cecil Medicine 6 & 29 \\
\hline Principles of Critical Care ${ }^{14}$ & 21 \\
\hline Essentials of Mechanical Ventilation $^{12}$ & 19 \\
\hline Physical Examination \& Health Assessment ${ }^{8}$ & 17 \\
\hline Miller's Anesthesia ${ }^{22}$ & 13 \\
\hline \multicolumn{2}{|c|}{$\begin{array}{l}\text { * Books earned one point for each }+ \text { sign in Table } 4 \text {. The total number of possible points } \\
\text { was } 52 \text {. } \\
\dagger \text { The UptoDate analysis earned this score only when the pediatric sections were examined. } \\
\text { and there was only a section on respiratory distress in mechanically ventilated patients. }\end{array}$} \\
\hline
\end{tabular}

textbooks mentioned grunting, and only one (5\%) proposed that it improved oxygenation by increasing intrinsic PEEP.

Diaphoresis. Out of the $10(18 \%)$ textbooks that mentioned diaphoresis, 5 (24\%) described it as a sign of acute severe airway obstruction in patients with asthma or COPD. Three (14\%) textbooks mentioned it as a general sign of severe cardiopulmonary derangement. Two (10\%) textbooks described it as a sign of an increased metabolic rate.

Nasal Flaring. Out of $8(38 \%)$ textbooks that mentioned nasal flaring, $4(19 \%)$ described it as a sign of increased respiratory work or drive, and $4(19 \%)$ described it as a sign of respiratory distress. One (5\%) described it as a sign 


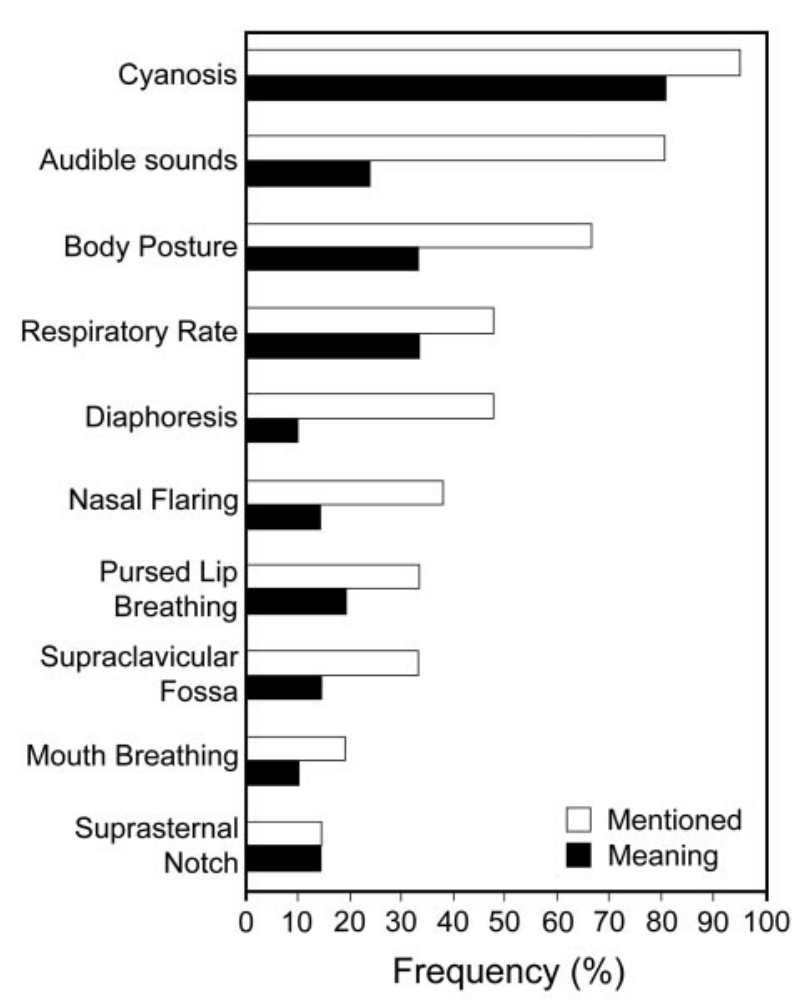

Fig. 1. Inspection signs.

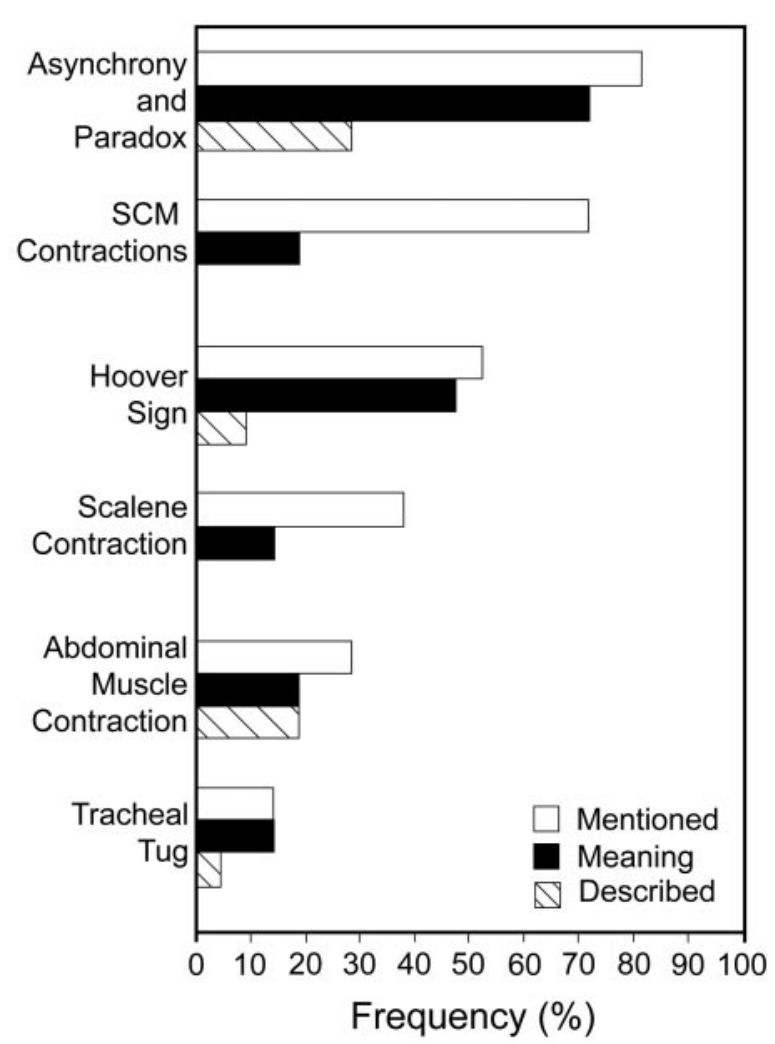

Fig. 2. Palpation signs. SCM = sternocleidomastoid. of obstruction of the nares in newborns and infants. Two (10\%) textbooks discussed aspects of its physiology.

Mouth Breathing and Gasping. Out of the 4 (19\%) textbooks that mentioned mouth breathing with gasping, one stated that it is a sign of supraglottitis, and 3 stated that it is a sign of respiratory distress. One textbook stated, "gasping respirations are a sign of poor oxygen delivery consequent to inadequate cardiac output." 20 One textbook provided more detail:

\begin{abstract}
At an early stage of respiratory distress, the mouth opens slightly and to a variable extent during inhalation. At a later stage, the mouth opens throughout the respiratory cycle. The patient may switch to mouth breathing perhaps to decrease respiratory work and physiologic dead-space ventilation. ${ }^{11}$
\end{abstract}

Pursed Lip Breathing. Seven (33\%) textbooks mentioned pursed lip breathing. Three books mentioned that it improves gas exchange in patients with COPD by preventing airway collapse. Four mentioned that it could be a sign of severe COPD, respiratory impairment, or COPD exacerbation.

Retraction of Supraclavicular Fossa. Seven (33\%) textbooks mentioned this sign. Four (19\%) mentioned it as a sign of respiratory distress or an increased work of breathing. Three (14\%) textbooks stated that it was due to wide swings in intrathoracic pressure.

Retraction of Suprasternal Fossa. Three (14\%) textbooks mentioned this sign. One described it as a sign of flail chest, and 2 explained that it suggests a large swing in pleural pressure and hence an increase in the work of breathing.

Sternocleidomastoid Muscle Contraction. Fifteen (71\%) textbooks mentioned sternocleidomastoid contraction. Of these, 7 (33\%) textbooks described its role as an accessory muscle of respiration. Three mentioned that it indicates an increased work of breathing or respiratory distress. One book stated, "the sternocleidomastoid muscles are not usually active during quiet breathing but are always active during at high lung volumes or high levels of ventilation." 18 Another book stated: "In general, their use appears to signify that the $\mathrm{FEV}_{1}$ is decreased to $30 \%$ of normal or less. In one study of asthmatic patients, sternocleidomastoid muscle retraction was the only sign that correlated with pulmonary function results, appearing at a $\mathrm{FEV}_{1}$ between 1 and $1.5 \mathrm{L.}$ " 10

Another book explained, "In patients with respiratory distress, sternomastoid recruitment can be phasic (during 


\section{Textbooks on the Evaluation of a Patient in Respiratory Distress}

inhalation) or tonic. Some patients hold their head off the pillow to enhance sternomastoid actions." 11

Scalene Muscle Contraction. Out of the $8(38 \%)$ textbooks that mentioned scalene muscle contraction, only 3 books described its pathophysiology. There was also disagreement if it was a primary or accessory muscle of respiration, 2 books considering it the former, while 5 considered it the latter. One book stated the scalene muscles are recruited during high minute ventilation requirements or when excessive inspiratory work is required. ${ }^{20}$ None explained the method to palpate scalene muscle contraction.

Tracheal Tug. Out of the $4(19 \%)$ textbooks that mentioned this sign, one described the method to detect it. All 3 described it as a sign of obstruction. Two stated that it is due to a great downward pull of the diaphragm.

Hoover's Sign. Eleven (52\%) textbooks mentioned Hoover's sign. Ten (48\%) described its pathophysiology, and 2 described the method to detect it. Six books (29\%) described it as a sign of COPD and $4(20 \%)$ as a sign of emphysema. One book stated:

\begin{abstract}
Hyperinflation shortens the diaphragm and changes its shape to a flatter one in which the horizontal fibers do not generate the normal expanding action on the thorax but rather an inward retraction of the lower part of the rib cage (eg, Hoover's sign in COPD). These changes, coupled with increased airway resistance and decreased lung and chest wall compliance, result in increased work of breathing. ${ }^{6}$
\end{abstract}

Thoracoabdominal Asynchrony or Paradox. Seventeen $(81 \%)$ textbooks mentioned thoracoabdominal asynchrony or paradox. Two described it as a sign of increased respiratory muscle load. The remainder of the descriptions invoked diaphragmatic dysfunction, albeit with slightly different wording: one textbook described it as a sign of diaphragmatic paralysis, 2 textbooks described it as a sign of diaphragmatic weakness, and 7 described it as a sign of diaphragmatic fatigue. One textbook mentioned it as a normal finding in preterm and newborn infants. Respiratory paradox and asynchrony were also mentioned as signs of hyperinflation, increased work of breathing, and imminent respiratory failure by 3 different textbooks.

Abdominal Muscle Contraction. Six (28\%) textbooks mentioned abdominal muscle contraction. All 6 mentioned it as an expiratory muscle, but 3 books stated that it also assists in inspiration. One book mentioned it as a sign of respiratory distress. One book mentioned it as a manifestation of increased inspiratory muscle load and one book associated it with diaphragmatic paralysis:
In addition to their role in expiration, the abdominal muscles in coordinated use appear to facilitate inspiration by the following 2 mechanisms. First, by reducing FRC [functional residual capacity] so that the elastic recoil of the respiratory system is inspiratory, work done by the expiratory muscles may be recovered during inspiration. Second, it has been argued that elongation of inspiratory muscles may place them at a more advantageous operating length and thus improve the efficacy of pressure generation for a given neural activation during inspiration. ${ }^{18}$

Respiratory Rate. Out of $10(48 \%)$ books that mentioned respiratory rate, 7 (35\%) defined its normal range. The normal ranges were listed as: $12-20,{ }^{6} 10-20,{ }^{8} 14-$ $20,{ }^{7} 10-14,{ }^{9} 12-18,{ }^{21} 10-20,{ }^{10}$ and $10-22$ in $2 .{ }^{11,15}$ One book stated that it increases with age, ${ }^{10}$ and one stated that there is no variability with age. ${ }^{15}$ Three textbooks described the proper method of counting it, which was consistently described as measuring for at least 30 seconds, and preferably 60. Two books mentioned the importance of an abnormal respiratory rate. One textbook went into detail, defining a baseline normal respiratory rate for patients with various respiratory diseases.

Cyanosis. All except one book (95\%) mentioned cyanosis, and $17(81 \%)$ books discussed its meaning. Most books described it as a sign of hypoxemia or dyshemoglobinemia, and that it is not a reliable sign of hypoxemia.

\section{Internet Resources}

We also searched the most commonly used internet resources by our house staff: UptoDate (www.uptodate.com) has original content, and $M D$ Consult (www.mdconsult. com) merely reproduces textbooks in an online format. In Table 1 we have included whether the textbooks we reviewed were available online, which included MD Consult. The searches were performed in April 2011.

UptoDate had topic reviews on the respiratory system and respiratory distress, and indications for intubation. It did not have a topic review on respiratory failure. Its only topic review on indications for mechanical ventilation was limited to the pediatric population only.

It had an article that mentioned respiratory rate and the interpretation of abnormal values. See Table 5 for the other signs that were mentioned in UptoDate.

The "app stores" of both Android and Apple yielded no results. Most applications were merely advanced cardiac life support (ACLS) algorithms or bedside calculators (arterial blood gas interpreters, arterial-alveolar gradient calculators, etc). 


\section{Textbooks on the Evaluation of a Patient in Respiratory Distress}

Table 5. Results of UptoDate Analysis

\begin{tabular}{|c|c|c|}
\hline Sign, Chapter, or Topic Review & $\begin{array}{c}\text { Present }(+) / \\
\text { Absent }(-)\end{array}$ & $\begin{array}{l}\text { Only in } \\
\text { Pediatric } \\
\text { Section }\end{array}$ \\
\hline Topic review on respiratory system & + & \\
\hline Topic review on respiratory distress & + & \\
\hline Topic review on respiratory failure & - & \\
\hline Indications for mechanical ventilation & + & \\
\hline Indications for intubation & + & \\
\hline \multicolumn{3}{|l|}{ Inspection Signs } \\
\hline \multicolumn{3}{|l|}{ Respiratory rate } \\
\hline Normal range & + & \\
\hline Interpretation of abnormal values & + & \\
\hline \multicolumn{3}{|l|}{ Body posture } \\
\hline Mentioned & + & \\
\hline \multicolumn{3}{|l|}{ Described } \\
\hline Meaning & + & \\
\hline Detection & + & + \\
\hline \multicolumn{3}{|l|}{ Audible sounds } \\
\hline Mentioned & + & + \\
\hline \multicolumn{3}{|l|}{ Described } \\
\hline Meaning & + & + \\
\hline Detection & + & + \\
\hline \multicolumn{3}{|l|}{ Diaphoresis } \\
\hline Mentioned & + & \\
\hline \multicolumn{3}{|l|}{ Described } \\
\hline Meaning & + & \\
\hline Detection & + & \\
\hline \multicolumn{3}{|l|}{ Nasal flaring } \\
\hline Mentioned & + & + \\
\hline \multicolumn{3}{|l|}{ Described } \\
\hline Meaning & + & + \\
\hline Detection & + & + \\
\hline \multicolumn{3}{|l|}{ Cyanosis } \\
\hline Mentioned & + & + \\
\hline \multicolumn{3}{|l|}{ Described } \\
\hline Meaning & + & + \\
\hline Detection & + & + \\
\hline \multicolumn{3}{|l|}{ Mouth breathing } \\
\hline Mentioned & - & \\
\hline \multicolumn{3}{|l|}{ Described } \\
\hline Meaning & - & \\
\hline Detection & - & \\
\hline \multicolumn{3}{|l|}{ Pursed Lip Breathing } \\
\hline Mentioned & - & \\
\hline \multicolumn{3}{|l|}{ Described } \\
\hline Meaning & - & \\
\hline Detection & - & \\
\hline \multicolumn{3}{|l|}{ Retraction of the suprasternal notch } \\
\hline Mentioned & + & \\
\hline \multicolumn{3}{|l|}{ Described } \\
\hline Meaning & + & \\
\hline Detection & + & \\
\hline \multicolumn{3}{|l|}{ Retraction of the supraclavicular fossa } \\
\hline Mentioned & + & \\
\hline \multicolumn{3}{|l|}{ Described } \\
\hline Meaning & + & \\
\hline Detection & + & \\
\hline
\end{tabular}

Table 5. Results of UptoDate Analysis (Continued)

\begin{tabular}{|c|c|c|}
\hline Sign, Chapter, or Section & $\begin{array}{c}\text { Present (+)/ } \\
\text { Absent (-) }\end{array}$ & $\begin{array}{l}\text { Only in } \\
\text { Pediatric } \\
\text { Section }\end{array}$ \\
\hline \multicolumn{3}{|l|}{ Hoover's sign } \\
\hline Mentioned & + & + \\
\hline \multicolumn{3}{|l|}{ Described } \\
\hline Meaning & + & + \\
\hline Detection & - & \\
\hline \multicolumn{3}{|l|}{ Palpation Signs } \\
\hline \multicolumn{3}{|l|}{ Paradoxical breathing } \\
\hline Mentioned & + & + \\
\hline Described & + & \\
\hline Meaning & - & + \\
\hline \multicolumn{3}{|l|}{ Detection } \\
\hline \multicolumn{3}{|c|}{ Exhalatory abdominal muscle contraction } \\
\hline Mentioned & + & \\
\hline Described & + & \\
\hline Meaning & - & \\
\hline \multicolumn{3}{|l|}{ Detection } \\
\hline \multicolumn{3}{|l|}{ Scalene contraction } \\
\hline Mentioned & - & \\
\hline Described & - & \\
\hline Meaning & - & \\
\hline Detection & - & \\
\hline \multicolumn{3}{|l|}{ Sternocleidomastoid contraction } \\
\hline Mentioned & + & \\
\hline \multicolumn{3}{|l|}{ Described } \\
\hline Meaning & + & \\
\hline Detection & - & \\
\hline \multicolumn{3}{|l|}{ Tracheal tug } \\
\hline Mentioned & - & \\
\hline Described & - & \\
\hline Meaning & - & \\
\hline Detection & - & \\
\hline
\end{tabular}

\section{Discussion}

The method to detect signs of respiratory distress, as described in 21 major medical textbooks, is extremely variable. Textbooks frequently mention the signs without a detailed discussion of their meaning. The pathophysiologic explanations offered are sometimes outdated and contradictory. These deficiencies occur despite the fact that all the sampled textbooks have a chapter on the respiratory system; the majority of them have a chapter or a section on either respiratory failure, the evaluation of respiratory distress, or the indications for intubation and mechanical ventilation.

Respiratory rate is an important variable in critical care, and was poorly represented in our sample. It is incorporated in many scoring systems that predict mortality, ${ }^{25}$ it is part of many clinical prediction rules (CURB-65 [confusion, urea nitrogen, respiratory rate, blood pressure, $\geq 65$ years of age]), ${ }^{26}$ and is influential in making deci- 


\section{Textbooks on the Evaluation of a Patient in Respiratory Distress}

sions about intubation and extubation of patients with respiratory conditions. ${ }^{27,28}$ Despite this importance, the majority of the textbooks failed to mention its normal range and did not describe its role in decision making.

Cyanosis is the most frequently mentioned sign in the reviewed textbooks, and it usually receives the longest discussion. It is, however, an unreliable sign, ${ }^{29}$ and its occurrence is dependent on hemoglobin concentration. ${ }^{30}$ In addition, the widespread treatment of unstable patients with oxygen probably reduces the likelihood of detecting it. It is emblematic of textbooks that the most frequently mentioned sign is also the least useful.

Thoracoabdominal asynchrony or paradox was mentioned by the majority of the reviewed textbooks. Unfortunately, despite its importance, the discussion of its meaning was inconsistent. Some textbooks described it as a sign of increased load, while others described it as a signs of diaphragmatic paralysis, weakness, or fatigue. Paradoxical movement of the chest and abdomen are well documented in the setting of bilateral diaphragmatic paralysis. ${ }^{31}$ On the other hand, despite the clear meaning of the term "fatigue," the exact nature of diaphragmatic fatigue in patients with acute respiratory failure remains controversial. ${ }^{32}$ In fact, paradox and asynchrony in patients with acute respiratory failure is probably a sign of increased load. ${ }^{33}$

Furthermore, none of the textbooks described how to detect all of the signs evaluated in this study. In fact none of the books described how to detect sternocleidomastoid or scalene contraction, despite being mentioned by the majority of the books as important accessory muscles activated in patients with respiratory distress. One explanation could be that the authors of these books believed that these signs can be detected merely by observation. Palpation of these muscles to ascertain their contraction is probably more reliable. ${ }^{34}$ Furthermore, the scalene muscle is not an accessory muscle, as it contracts during resting in normal individuals. ${ }^{35}$

Our study has 2 limitations: The number of selected textbooks was small, and they were selected according to their availability to the authors and the recommendations of colleagues. An alternative approach might be to select the bestselling books in the selected disciplines that care for patients with respiratory distress. ${ }^{36}$ However, there is no readily available "ranking" of bestselling textbooks across merchants. Individual merchant's rankings are also subject to bias. We think that the selected textbooks are representative of the areas of interest, and we doubt that an alternative approach would lead to significantly different results. The editions of textbooks we reviewed spanned a time frame of 13 years, but since there is very little active research on the bedside manifestations of respiratory failure, we do not believe the publication year biased the results.
We identified the signs by compiling them from the selected books, as none of the books included all the signs. Furthermore, currently there is no standard for the minimum signs that need to be detected to identify important respiratory distress, and there is no gold standard by which to compare these results.

\section{Conclusions}

In conclusion, the content of contemporary textbooks on the physical examination of patients in respiratory distress is inadequate and sometimes inaccurate. Respiratory distress is an urgent condition that junior physicians (the first-line personnel in a teaching hospital) should be able to recognize early. Unfortunately, by its very nature, it is also a condition where bedside teaching is difficult. A more standardized approach to the assessment of respiratory distress would be useful for the education of house staff.

\section{REFERENCES}

1. Spiro SG, Albert RK, Jett JR. Clinical respiratory medicine, 3rd edition. Philadelphia: Mosby-Elsevier; 2008.

2. Kovacs G, Law JA. Airway management in emergencies. New York: McGraw-Hill; 2008.

3. Massarelli JJ. Harrison's principles of internal medicine (book review). JAMA 1998;279(19):1578.

4. Weaver LK. Principles of critical care (book review). JAMA 1999; 281(2):193.

5. Fauci A, Braunwald E, Hauser S, Longo DL, Jameson J, editors. Harrison's principles of internal medicine, 17th edition. New York: McGraw-Hill; 2008.

6. Goldman L, Ausiello DA, editors. Cecil medicine, 23rd edition. Philadelphia: Saunders/Elsevier; 2008.

7. Bickley L, Szilagyi PG, editors. Bates' guide to physical examination and history taking, 9th edition. Philadelphia: Lippincott Williams \& Wilkins; 2007.

8. Jarvis C. Physical examination \& health assessment, 5th edition. St Louis: Saunders/Elsevier; 2008.

9. Swartz M. Textbook of physical diagnosis: history and examination, 5th edition. Philadelphia: Saunders; 2006.

10. Orient JM. Sapira's art \& science of bedside diagnosis, 3rd edition. Philadelphia: Lippincott Williams \& Wilkins; 2005.

11. Tobin MJ, editor. Principles and practice of mechanical ventilation, 2nd edition. New York: McGraw-Hill; 2006.

12. Hess DR, Kacmarek RM, editors. Essentials of mechanical ventilation, 2nd edition. New York: McGraw-Hill; 2002.

13. Pilbeam S, Cairo JM, editors. Mechanical ventilation : physiological and clinical applications, 4th edition. St Louis: Mosby/Elsevier; 2006.

14. Hall JB, Schmidt GA, Wood L, editors. Principles of critical care, 3rd edition. New York: McGraw-Hill; 2005.

15. Tobin MJ, editor. Principles and practice of intensive care monitoring. New York: McGraw-Hill; 1998.

16. Irwin R, Rippe JR, editors. Irwin and Rippe's intensive care medicine, 6th edition. Philadelphia: Wolters Kluwer Health/Lippincott Williams \& Wilkins; 2008. 


\section{Textbooks on the Evaluation of a Patient in RespiRatory Distress}

17. Parrillo J, Dellinger RP, editors. Critical care medicine: principles of diagnosis and management in the adult, 3rd edition. Philadelphia: Mosby/Elsevier; 2008.

18. Mason RJ, Broaddus VC, Murray JF, Nadel JA, editors. Murray and Nadel's textbook of respiratory medicine, 4th edition. Philadelphia: Saunders; 2005.

19. Fraser R, Muller NL, Colman NC, Paré PD, editors. Fraser and Paré's diagnosis of diseases of the chest, 4th edition. Philadelphia: WB Saunders; 1999.

20. Dantzker D, MacIntyre NR, Bakow ED editors. Comprehensive respiratory care. Philadelphia: WB Saunders; 1995.

21. Wilkins RJ, Stoller JK, Scanlan CL, editors. Egan's fundamentals of respiratory care, 8th edition. St Louis: Mosby; 2003.

22. Miller R, editor. Miller's Anesthesia, 6th edition. Edinburgh: Churchill Livingstone; 2005.

23. Wolfson A. Harwood-Nuss' clinical practice of emergency medicine, 4th edition. Philadelphia: Lippincott Williams \& Wilkins; 2005.

24. Tintinalli J, Kelen GD, Stapczynski JS. Emergency medicine: a comprehensive study guide, 6th edition. New York: McGraw-Hill; 2004.

25. Knaus WA, Draper EA, Wagner DP, Zimmerman JE. APACHE II: a severity of disease classification system. Crit Care Med 1985; 13(10):818-829.

26. Lim WS, van der Eerden MM, Laing R, Boersma WG, Karalus N, Town GI, et al. Defining community acquired pneumonia severity on presentation to hospital: an international derivation and validation study. Thorax 2003;58(5):377-382.
27. Yang KL, Tobin MJ. A prospective study of indexes predicting the outcome of trials of weaning from mechanical ventilation. N Engl J Med 1991;324(21):1445-1450.

28. Pontoppidan H, Geffin B, Lowenstein E. Acute respiratory failure in the adult. N Engl J Med 1972;287(14):690-698.

29. Comroe JH Jr, Bothelo S. The unreliability of cyanosis in the recognition of arterial anoxemia. Am J Med Sci 1947;124(1):1-6.

30. Martin L, Khalil H. How much reduced hemoglobin is necessary to generate central cyanosis? Chest 1990;97(1):182-185.

31. Gibson GJ. Diaphragmatic paresis: pathophysiology, clinical features, and investigation. Thorax 1989;44(11):960-970.

32. Laghi F, Tobin MJ. Disorders of the respiratory muscles. Am J Respir Crit Care Med 2003;168(1):10-48.

33. Tobin MJ, Perez W, Guenther SM, Lodato RF, Dantzker DR. Does rib cage-abdominal paradox signify respiratory muscle fatigue? J Appl Physiol 1987;63(2):851-860.

34. Maitre B, Similowski T, Derenne JP. Physical examination of the adult patient with respiratory diseases: inspection and palpation. Eur Respir J 1995;8(9):1584-1593.

35. Campbell EJ. The role of the scalene and sternomastoid muscles in breathing in normal subjects; an electromyographic study. J Anat 1955;89(3):378-386.

36. Rabow MW, Hardie GE, Fair JM, McPhee SJ. End-of-life care content in 50 textbooks from multiple specialties. JAMA 2000;283(6): 771-778. 